\title{
Effect of meteorological factors and Air Quality Index on the COVID-19 epidemiological characteristics: an ecological study among 210 countries
}

\author{
Mohebat Vali $^{1}$ - Jafar Hassanzadeh ${ }^{2} \cdot$ Alireza Mirahmadizadeh $^{3} \cdot$ Mohammad Hoseini $^{4} \cdot$ Samaneh Dehghani $^{5}$. \\ Zahra Maleki $^{1}$ - Fabiola Méndez-Arriaga ${ }^{6} \cdot$ Haleh Ghaem $^{7}$
}

Received: 12 February 2021 / Accepted: 3 May 2021 / Published online: 22 May 2021

(C) The Author(s), under exclusive licence to Springer-Verlag GmbH Germany, part of Springer Nature 2021

\begin{abstract}
The survival of COVID-19 in different environments may be affected by a variety of weather, pollution, and seasonal parameters. Therefore, the present study aims to conduct an ecological investigation on COVID-19 average growth rate of daily cases and deaths influenced by environmental factors (temperature, humidity, and air pollution) using a sample size of adjusted cumulative incidence of daily cases and deaths based on five 60-day periods. Research data was gathered on official websites, including information on COVID-19, meteorological data, and air pollution indicators from December 31, 2019, to October 12, 2020, from 210 countries. Spearman correlation and generalized additive model (GAM) were used to analyze the data. During the observed period, the COVID-19 average growth rate of daily cases $(\mathrm{r}=-0.08, P=0.151)$ and deaths $(\mathrm{r}=-0.09, P=0.207)$ were not correlated with humidity. Also, there was a negative relationship between the COVID-19 average growth rate of new cases and deaths with the Air Quality Index (AQI) and wind (new cases and wind: $\mathrm{r}=-0.25, P=0.04$ ). Furthermore, the data related to the first and second 60 day of the adjusted cumulative incidence of COVID-19 daily cases and deaths were not associated with humidity and Air Quality Index (AQI). The result of GAM showed the effect of AQI on the average growth rate of COVID-19 new cases and deaths. This study provides evidence for a positive relationship between COVID-19 daily cases, deaths, and AQI.
\end{abstract}

Keywords Humidity $\cdot$ COVID-19 $\cdot$ Meteorological concepts $\cdot$ Air pollution

Responsible Editor: Lotfi Aleya

Haleh Ghaem

ghaemh@sums.ac.ir

Mohebat Vali

mohebatvali@gmail.com

Jafar Hassanzadeh

jafarabolhasan@yahoo.com

Alireza Mirahmadizadeh

mirahmadia@sums.ac.ir

Mohammad Hoseini

hoseini2174@gmail.com

Samaneh Dehghani sama22kv@gmail.com

Zahra Maleki

maleki5146@gmail.com

Fabiola Méndez-Arriaga

FMendez@conacyt.mx
1 Student Research Committee, Shiraz University of Medical Sciences, Shiraz, Iran

2 Department of Epidemiology, Shiraz University of Medical Sciences, Shiraz, Iran

3 Non-communicable Diseases Research Center, Shiraz University of Medical Sciences, Shiraz, Iran

4 Research Center for Health Sciences, Institute of Health, Department of Environmental Health, School of Health, Shiraz University of Medical Sciences, Shiraz, Iran

5 Department of Environmental Health Engineering, School of Health, Shiraz University of Medical Sciences, Shiraz, Iran

6 Consejo Nacional de Ciencia y Tecnología, Universidad Nacional Autónoma de México, Mexico, Mexico

7 Research Center for Health Sciences, Institute of Health, Department of Epidemiology, School of Health, Shiraz University of Medical Sciences, Shiraz, Iran 


\section{Introduction}

Over the last two decades, the spread of viral epidemics has severely threatened the health of humans and societies. The current prevalence of COVID-19 has led the World Health Organization (WHO) to announce the disease as a global epidemic. As of April 5, 2020, the WHO reported that about 206 countries were suffering active cases of COVID-19 (https:// www.worldometers.info/coronavirus/). The current global death rate of COVID-19 is estimated to be $3.7 \%$, which is lower than SARS-CoV and MERS-CoV, with $10 \%$ and $37 \%$ death rates, respectively. The principal challenge with this group of coronavirus families and similar infectious agents is the lack of an effective drug or vaccine and the extended time needed for research alongside (Lai et al. 2020).

One way of spreading respiratory diseases is through airborne dust. Microorganisms in the air or dust appear to be associated with infectious diseases ( $\mathrm{Yu}$ et al. 2004). Inhalation of small virus particles can carry the virus to deeper areas of the alveoli and chips that, in turn, increases the risk of infection spread. Therefore, the spread of the COVID-19 virus in the long term is due to the spread of this virus through airborne dust (Qu et al. 2020). Furthermore, high air pollution levels may increase people's susceptibility to more serious symptoms and respiratory distress. Also, air-oxidizing contaminants interfere with the immune system and weaken the lungs' ability to remove the virus. Simultaneous inhalation of chemical contaminants through the COVID-19 virus may also exacerbate the level of infection (Yousefi et al. 2021; Qu et al. 2020; Yu et al. 2004).

Some of the previous studies have demonstrated that temperature and its changes may affect the prevalence of acute respiratory syndrome (SARS). A study in Korea reported that the risk of influenza increased significantly with daily decreases in temperature and humidity. Besides, diurnal temperature range (DTR) and temperature range were associated with death respiratory diseases (Park et al. 2020). A few other studies have reported an inverse association between COVID19 and meteorological factors; that is, as the temperature rises, the spread of the disease decreases (Wang et al. 2020a, b).

Moreover, studies have shown that the case-fatality rate (CFR) of COVID 19 increases simultaneously with the increase in particulate matter concentration for the aerodynamic diameter of $10 \mu \mathrm{m}$ or less $\left(\mathrm{PM}_{10}\right)$ (Yao et al. 2020).

There is no doubt that effective response, control, and prevention of new infectious diseases require mutual and consistent international cooperation and information exchange. Nevertheless, more research is needed to contribute to the knowledge of COVID-19. Therefore, the present comprehensive study aims to conduct an ecological investigation on the COVID-19 average growth rate of new cases and deaths influenced by environmental factors (temperature, humidity, and air pollution) using the data covering 210 countries collected on five 60-day periods. It is the only comprehensive study that investigates ecological and environmental factors on COVID-19 covering 210 countries affected by the disease.

\section{Methods}

\section{Growth rate of daily cases and deaths}

This study examined the data in two ways:

a) First, the average AQI, temperature, humidity, wind, pressure, growth rate case, and death in 210 countries from December 31, 2019, to October 12, 2020, were calculated based on the numbers of daily cases and deaths of coronavirus disease. For example, the growth rate for the second day is calculated with the number of patients (or death cases) of the second day divided by the same number of the first day. Accordingly, the growth rate for all days was calculated.

b) Second, the average total growth rate in all countries was calculated from December 31, 2019, to October 12, 2020.

Data of 210 countries (55 African, 49 American, 44 Asian, 54 European, and 8 Oceania countries listed in supplementary.1 information), including daily cases and death numbers of coronavirus disease, were collected from the official websites, meteorological data (maximum, minimum, and mean temperature, humidity, pressure, and wind speed), and air pollution indicators $\left(\mathrm{PM}_{2.5}, \mathrm{PM}_{10}, \mathrm{O}_{3}, \mathrm{NO}_{2}, \mathrm{SO}_{2}, \mathrm{CO}\right)$. Air Quality Index (AQI) was based on the measurement of particulate matters $\left(\mathrm{PM}_{25}\right.$ and $\left.\mathrm{PM}_{10}\right)$ and $\mathrm{O}_{3}, \mathrm{NO}_{2}, \mathrm{SO}_{2}, \mathrm{CO}$ emissions.

Most stations monitor both $\mathrm{PM}_{10}$ and $\mathrm{PM}_{2.5}$ data, while few stations only monitor $\mathrm{PM}_{10}$. The US Environmental Protection Agency (EPA) uses this system to convert the raw pollutant measurements in ppb or $\mu \mathrm{g} / \mathrm{m}^{3}$ into AQI (ranging between 0 and 500). The nowcast concept redefines the "24-hour average (RA24H)" which is applied to convert emission concentrations to AQI. AQI scale determines the levels of health concern (i.e., unhealthy, moderate, good, etc.) for a 24$\mathrm{h}$ exposure. For instance, an AQI of 188 (unhealthy) will negatively affect if an individual stays outside for $24 \mathrm{~h}$. All the calculations were performed on an hourly basis. For example, the reported AQI at 8 AM was based upon measurements performed between $7 \mathrm{AM}$ and $8 \mathrm{AM}$ (Zhu et al. 2020). Table S.1 has shown Air Quality Index scale, according to the US-EPA 2016 standard. The equation below is used to convert concentrations into AQI (Wu et al. 2020):

$I=\frac{I_{\text {high }}-I_{\text {low }}}{C_{\text {high }}-C_{\text {low }}}\left(C-C_{\text {low }}\right)+I_{\text {low }}$ 
where,

I the (Air Quality) index,

$C$ the pollutant concentration,

$C_{\text {low }}$ the concentration breakpoint that is $\leq C$,

$C_{\text {high }}$ the concentration breakpoint that is $\geq C$,

$I_{\text {low }}$ the index breakpoint corresponding to $C_{\text {low }}$,

$I_{\text {high }}$ the index breakpoint corresponding to $C_{\text {high }}$.

Besides, the term "edf" was calculated to indicate whether the relationship is linear or nonlinear: if "edf" is 1 , the relationship is linear according to the following equation (Wood 2017):

$f(x ; \theta, \lambda)=c(x, \lambda) \exp (\lambda\{\theta x-k(\theta)\}), \quad \theta \in, \lambda \in \Lambda$

where, called the canonical space, is an open interval that contains $0 \wedge \subset(0, \infty)$ is called the index set, $\boldsymbol{\theta}$ and $\boldsymbol{\lambda}$ are called the canonical and index parameters, respectively; and $K$ is a smooth function.

\section{Adjusted cumulative incidence of daily cases and deaths}

The cumulative incidence of daily cases and deaths were adjusted according to the population size of the countries. The cumulative incidence during the study (December 31, 2019, to October 12, 2020) was calculated for five intervals of 60 consecutive days. The total number of intervals per country was a function of the start of the epidemic. The values in the fourth and fifth 60 days, for all countries, were very low nearly zero, so they were not taken into account. Then the calculated numbers were converted into 100,000 people.

The daily and the cumulative number of cases and deaths caused by coronavirus disease (COVID-19) deaths were collected on the following official websites: https:// ourworldindata.org, https://maps.isc.gov.ir/covid19/, and https://www.worldometers.info/coronavirus//.

The simultaneous daily meteorological data and air pollution indicators were obtained from https://waqi.info/;https:// ourworldindata.org/outdoor-air-pollution and https://www. wunderground.com/history.

\section{Statistical analysis}

Spearman correlation and generalized additive model (GAM) were used to determine the statistical association between meteorological data and air pollution indicators with COVID-19 average growth rate of daily cases and deaths. The plot modeling between meteorological data and air pollution indicators with COVID-19 average growth rate of daily cases and deaths and sample size of adjusted cumulative cases and deaths showed the confidence interval for the GAM. We also reported edf, which indicates whether the relationship is linear or nonlinear. All of the statistical analyses were two-sided with a significance level of $5 \%$. All analyses were conducted using R software (version 3.5.0) with the GAM fitted by the "mgcv" package (version 1.8-27).

\section{Results and discussion}

\section{Growth rate of new cases and deaths}

Table 1 shows the descriptive statistics of meteorological data, air pollution indicators, and the growth rate cases and deaths of coronavirus disease (COVID-19). During the observation period (December 31, 2019, to October 12, 2020), the number of COVID-19-related cases and deaths were 649,260 and $16,249,266$ in 210 countries, respectively. The average growth rate of COVID-19 cases, including incidence and deaths, was approximately 0.32 and 0.77 among 210 countries, respectively. The lowest (zero) average growth rate of COVID-19 incidence was related to Anguilla, Grenada, and Montserrat and the highest (2.99) to Bosnia and Herzegovina. The highest average growth rate of deaths was observed in Chile (1.69), Yemen (1.55), and Kyrgyzstan (1.52). Figure 1 shows COVID-19 average growth rate of new cases and daily deaths in 210 countries during the period of December 31, 2019, to October 12, 2020.

Concerning temperature, New Zealand had the lowest temperature $\left(1^{\circ} \mathrm{C}\right)$, and Qatar had the highest temperature $\left(43^{\circ}\right.$ C) in Asia. Tunisia reported the lowest humidity (6\%), and Bhutan and Mexico reported the lowest (723) and highest (1027) pressure (mbar), respectively. As to the air pollution, Belarus had the best air quality $(\mathrm{AQI}=4)$, while Uganda had the worst air quality (AQI = 184). In terms of wind $(\mathrm{mph})$, New Zealand registered the fastest wind speed of $136 \mathrm{mph}$.

The COVID-19 average growth rate of daily cases showed no correlation with humidity $(\mathrm{r}=-0.08, \mathrm{P}=0.151)$. Also, the average growth rate of daily deaths of COVID-19 was not associated with humidity ( $r=-0.09, P=0.207$ ). Instead, there was a negative correlation between the average growth rate of daily COVID-19 cases and deaths with the Air Quality Index (AQI) and wind (new cases and wind: $\mathrm{r}=-0.25, P=0.04$ ). Humidity was not correlated with AQI $(\mathrm{r}=-0.15, P=0.061)$ but with temperature $(\mathrm{r}=-0.31, P \leq 0.001)$. Furthermore, there was a strong positive correlation between $\mathrm{PM}_{10}$ and the average growth rate of daily COVID-19 cases $(\mathrm{r}=0.33, P \leq 0.001)$ and a trend toward a significant correlation with deaths ( $\mathrm{r}=0.13, P \leq 0.056)$. Also, there was a negative correlation between average precipitation and the average growth rate of daily COVID-19 cases ( $\mathrm{r}=$ $-0.15, P=0.058$ ) and a trend toward a significant correlation with deaths ( $\mathrm{r}=-0.18, P=0.018$ ) (Fig. 2).

According to the model, AQI had a nonlinear effect on COVID-19 average growth rate of daily cases $(P=0.018$ and edf $=1.751)$, pressure $(P=0.047$, edf $=1.00)$, and wind 
Table 1 Summary of COVID-19 average growth rate case and death, meteorological data

\begin{tabular}{|c|c|c|c|c|c|c|c|}
\hline \multirow[t]{2}{*}{ Variables } & & \multicolumn{6}{|c|}{ Daily measures } \\
\hline & & Mean \pm SD & Min & P 25 & Median & P 75 & Max \\
\hline \multicolumn{2}{|l|}{ Mean growth rate cases } & $.77 \pm 0.49$ & .00 & .35 & .81 & 1.12 & 2.99 \\
\hline \multicolumn{2}{|l|}{ Mean growth rate death } & $.32 \pm .38$ & .00 & .005 & .12 & .63 & 1.69 \\
\hline \multirow[t]{6}{*}{ Meteorological factors } & Temperature $\left({ }^{\circ} \mathrm{C}\right)$ & $24.66 \pm 6.16$ & 1 & 21.00 & 26.00 & 28.00 & 43 \\
\hline & Humidity (\%) & $69.14 \pm 22.65$ & 6 & 54.00 & 74.00 & 86.75 & 100 \\
\hline & Pressure (mbar) & $\begin{array}{r}1000.04 \\
\pm 43.67\end{array}$ & 723 & 1005.00 & 1011.00 & 1015.00 & 1027 \\
\hline & Wind (ms) & $8.41 \pm 11.46$ & 0 & 2.25 & 5.00 & 11.00 & 136 \\
\hline & AQI & $58.14 \pm 66.07$ & 4 & 25.00 & 45.00 & 71.50 & 184 \\
\hline & Average precipitation (mm per year) & $\begin{array}{l}470.96 \\
\quad \pm 254.34\end{array}$ & 51 & 241.00 & 535.00 & 656.75 & 934 \\
\hline
\end{tabular}

COVID-19 coronavirus disease, $S D$ standard deviance, Min minimum, $P 25$ 25th percentile, $P 75$ 75th percentile, Max maximum

$(P=0.00029$, edf $=1.953)$. On the other hand, COVID-19 average growth rate of daily deaths was affected by AQI ( $P$
$=0.0162$, edf $=1.00)$ and wind $(P \leq 0.001$, edf $=1.997)$. In Figure S.1 and S.2, plots of modeling were shown.
Fig. 1 COVID-19 average growth rate of new cases and daily deaths in 210 countries during the period of December 31,2019 to October 12, 2020. Note: A COVID-19 average growth rate of new case, $\mathbf{B}$ COVID-19 average growth rate of daily death

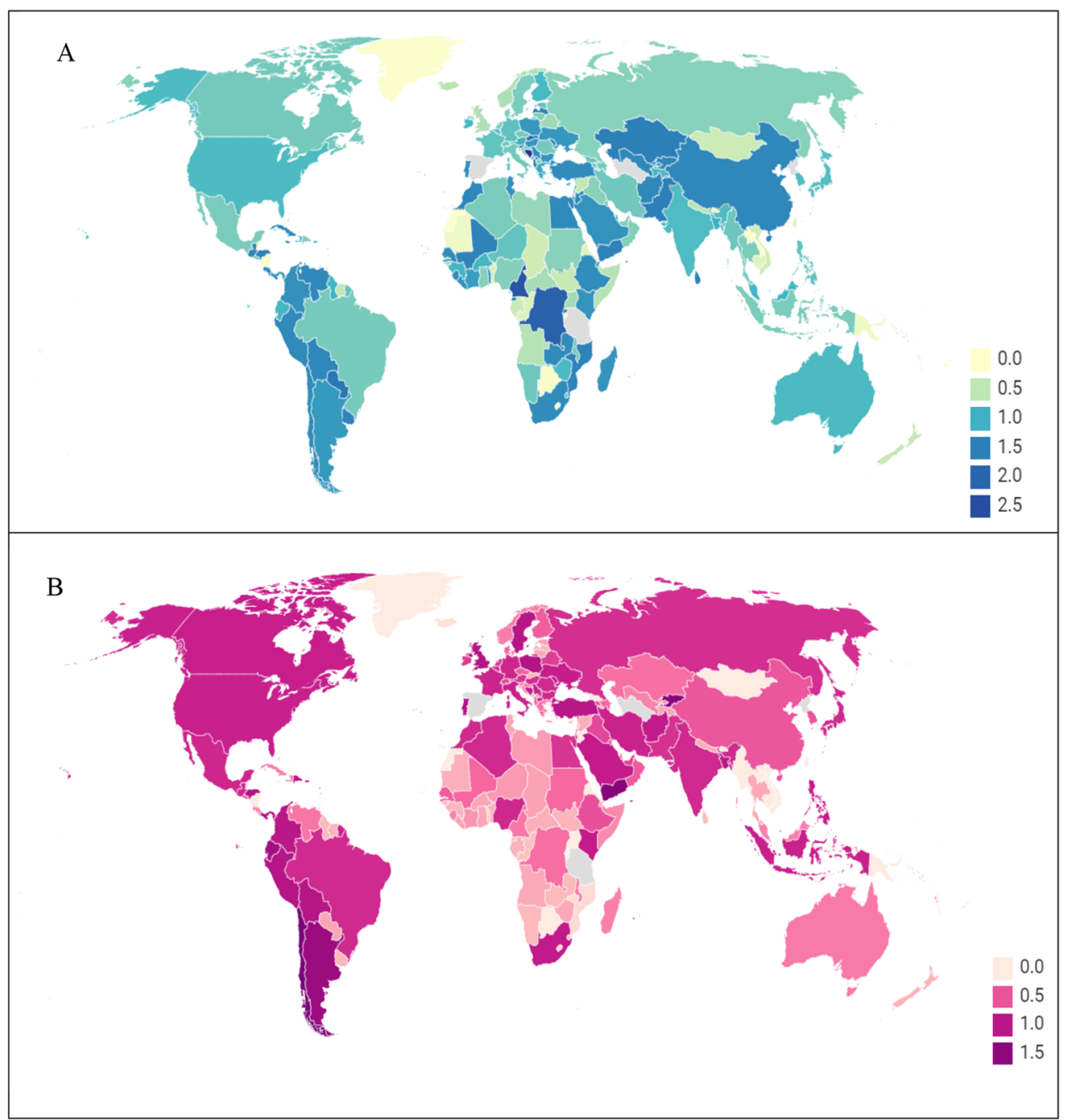




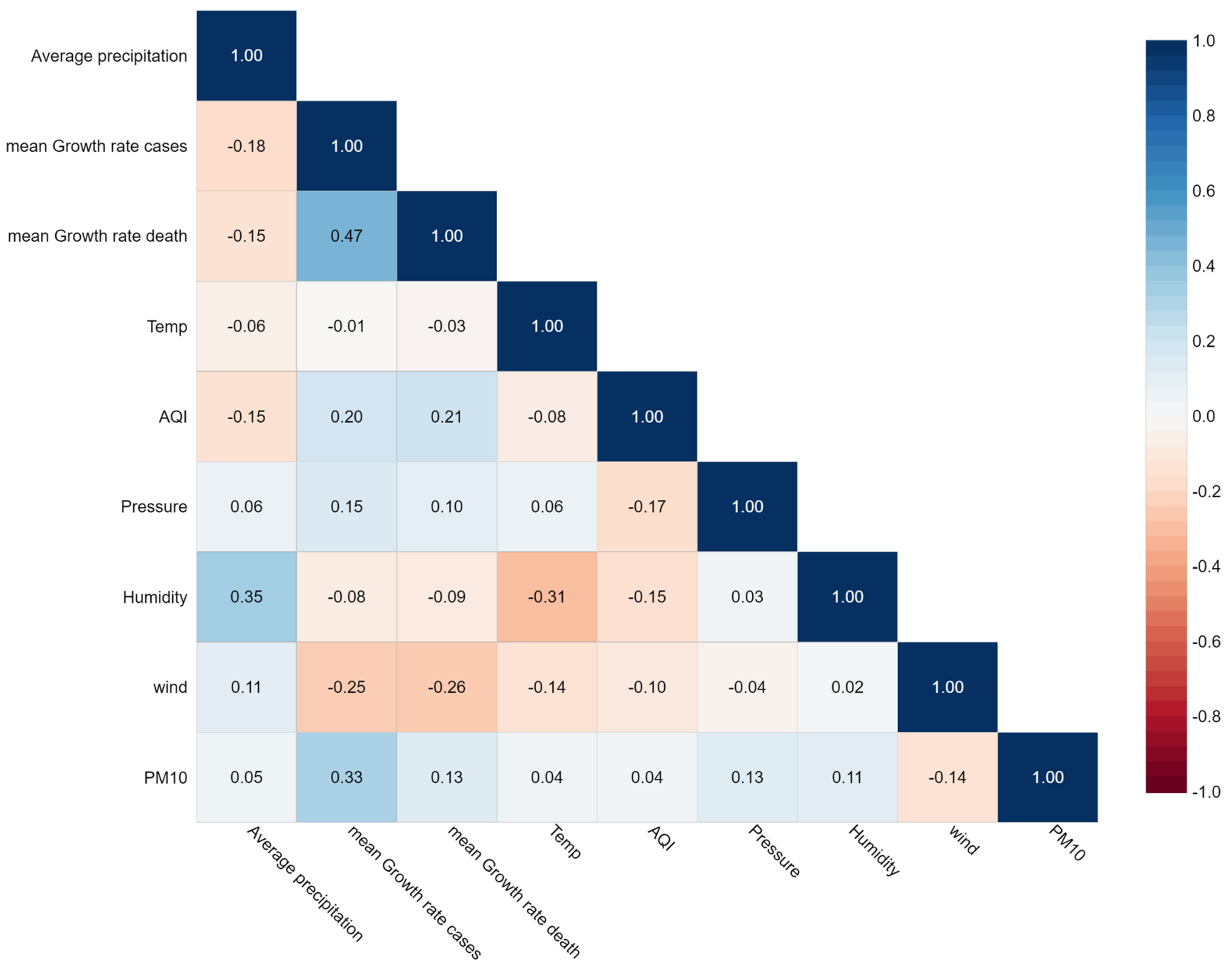

Fig. 2 Correlation between COVID-19 average growth rate of daily cases and death, meteorological factors, and air pollution indicators (Temp, temperature; AQI, Air Quality Index; PM10, particulate matter)

\section{Adjusted cumulative incidence of daily cases and deaths}

The highest cumulative incidence rate of daily COVID-19 cases in the first 60-day interval was related to Kyrgyzstan with $132,032.36$ per 100,000 people; in the second 60-day interval, Bahrain with 1647.43 per 100,000 people; and in the third 60-day interval, Qatar with 2647.81 per 100,000 people. In the fourth 60-day interval, the number was close to zero for all countries, but it was shown that in the last 60day interval, Tajikistan registered 600,000 cumulative incidence rates of daily cases per 100,000 people. The daily cases based on the population size of countries were reported. The highest cumulative rate of daily deaths in the first 60 consecutive days belonged to Peru with 46.80 per 100,000 people; in the second 60 consecutive days to San Marino with 104.49 per 100,000 people; and in the third 60 consecutive days to Andorra with 40.69 per 100,000 people.
The cumulative incidence rate of COVID-19 daily cases over the third 60-day interval was not correlated with humidity (first 60 days: $\mathrm{r}=-0.07, p=0.289$, second 60 days: $\mathrm{r}=-0.19, p=0.027$; third 60 days: $\mathrm{r}=-0.19, p=0.153)$. The cumulative rate of COVID-19 daily deaths during the third 60-day period showed no correlation with humidity (first 60 days: $\mathrm{r}=0.02, p=0.808$, second 60 days: $\mathrm{r}=-0.04, p=0.634$; third 60 days: $r=-0.02, p=0.882)$. The cumulative incidence rate of COVID-19 daily cases within the first and second 60day intervals was not correlated with Air Quality Index (AQI) (first 60 days: $\mathrm{r}=-0.02, p=0.264$, second 60 days: $\mathrm{r}=0.19, p=$ 0.185 ; third 60 days: $r=0.10, p=0.041$ ). Finally, the cumulative rate of COVID-19 daily deaths over the first and second 60-day intervals was not correlated with Air Quality Index (AQI) (first 60 days: $\mathrm{r}=0.17, p=0.260$; second 60 days: $\mathrm{r}=-0.04, p=0.268$; third 60 days: $\mathrm{r}=-0.07, p=0.024)$. Furthermore, the cumulative rate of COVID-19 daily cases and deaths from the first to the third 60-day intervals was 
correlated with $\mathrm{PM}_{10}$ (daily cases: first 60 days: $\mathrm{r}=0.34, P$ $\leq 0.001$; second 60 days: $\mathrm{r}=0.22, P \leq 0.001$; third 60 days: $\mathrm{r}=0.21, P \leq 0.001$; deaths: first 60 -day interval: $\mathrm{r}=0.51, P$ $\leq 0.001$; second 60-day interval: $\mathrm{r}=0.58, P \leq 0.001$; third 60 day interval: $\mathrm{r}=0.65, P \leq 0.001)$. The cumulative incidence rate of COVID-19 daily cases over the third 60-day interval was not correlated with average precipitation, but second and first 60-day interval was correlated (first 60 days: $\mathrm{r}=-0.17, p=$ 0.041 ; second 60 days: $\mathrm{r}=-0.23, p=0.013$; third 60 days: $\mathrm{r}=-0.16, p=0.053)$. The cumulative rate of COVID-19 daily deaths during the third 60-day period showed no correlation with average precipitation (first 60 days: $\mathrm{r}=0.08, p=0.323$; second 60 days: $\mathrm{r}=0.13, p=0.147$; third 60 days $\mathrm{r}=0.08, p$ $=0.384$ ) (see Fig. 3).

According to the model AQI, temperature, pressure, humidity, and wind had no non-linear effect on the cumulative incidence rate of daily COVID-19 cases in the first 60-day period (edf $=1$ for five variables). The cumulative incidence rate of daily COVID-19 cases over the second 60-day period was affected by temperature $(P=0.004$, edf $=3.25)$. The cumulative incidence rate of daily COVID-19 cases during the third 60-day interval was affected by temperature $(P=0.0002$, edf $=$ $8.73)$ and humidity $(P<0.001$, edf $=8.71)$. The cumulative incidence rate of daily COVID-19 cases in the fourth 60-day interval was zero. Cumulative incidence rate of daily COVID19 cases in the fifth 60 days was affected by temperature $(P=$ 0.025 , edf $=1.39)$, humidity $(P=0.023$, edf $=6.17)$, and pressure $(P<0.001$, edf $=8.83)$. In Figure S.3, S.4 and S.5, plots of modeling were shown.

The cumulative rate of COVID-19 daily deaths in the first 60-day interval was affected by AQI $(P=0.043$, edf= $1.00)$ and temperature $(P=0.001$, edf $=1.00)$. Besides, the cumulative rate of daily COVID-19 deaths in the second 60-day interval was affected by pressure $(P=0.012$, edf $=$ 7.32), and the cumulative rate of daily COVID-19 deaths in the third, fourth, and fifth 60-day intervals was not affected by meteorological factors and air pollution indicators.

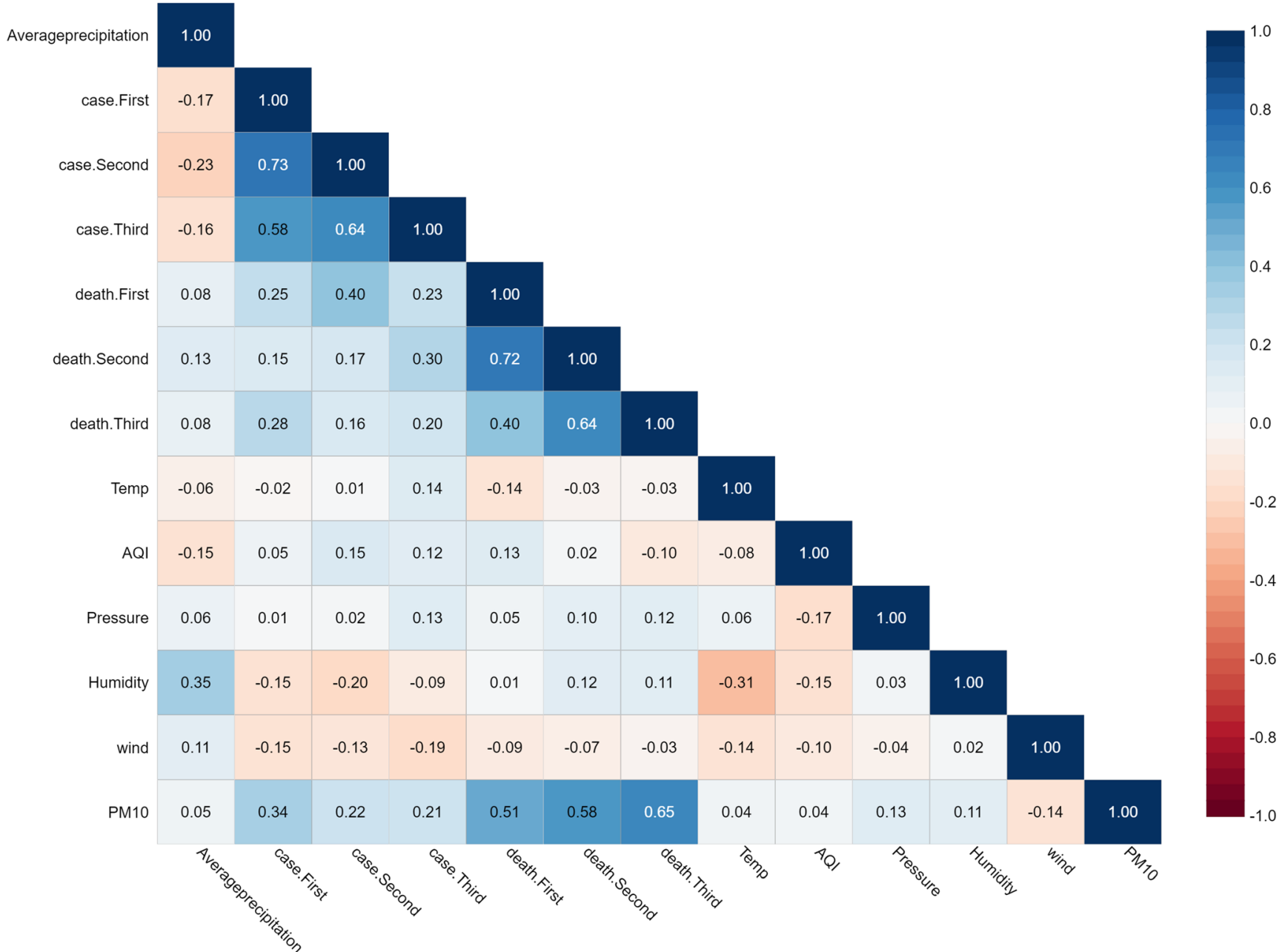

Fig. 3 Correlation between cumulative incidence of daily cases and death of COVID-19 based on the population size of countries separated in three 60-day intervals, meteorological factors, and air pollution indicators (number of $* 100000$ ) (temp, temperature; AQI, Air Quality Index; PM10, particulate matter) 
In this study, we developed a generalized additive model to investigate the relationship of meteorological factors and air pollution indicators with COVID-19 average growth rate of daily cases and deaths as well as the cumulative incidence rate of daily COVID-19 cases and deaths based on the population size of 210 countries spread over five consecutive 60-day intervals from December 31, 2019, to October 12, 2020.

Our results revealed that there was a negative, nonsignificant correlation between humidity and COVID-19 average growth rate of daily cases and deaths, but based on the population size of countries, daily COVID-19 cases and deaths from the first to the third 60-day interval did not correlate with meteorological measurements and air pollution indicators but with $\mathrm{PM}_{10}$.

Most importantly, this study rejects the emerging hypothesis that absolute humidity, even after temperature control, has been observed to be an important determinant of COVID-19 results. These results weaken the recent laboratory findings on guinea pigs and state-level epidemiologic evidence (Shaman et al. 2010; Shaman and Kohn 2009), but our key conclusion is that there is a non-linear relationship between AQI and COVID-19 average growth rate of daily cases and deaths.

Moreover, the cumulative incidence rate of COVID-19 daily cases and deaths, within the second 60-day interval, was affected by temperature, during the third 60-day interval by temperature and humidity and over the fifth 60 -day period by temperature, humidity, and pressure. The cumulative rate of COVID19 deaths in the first 60 days was influenced by AQI and temperature and pressure in the second 60 days. It appears that meteorological factors and air pollution indicators affect different epidemiological features and each of these variables has a significant impact on the disease in the first 60-day period.

According to the results, there was no relationship between temperature and COVID-19 average growth rate of daily cases and deaths. A linear relationship but not a significant one between ambient temperature and COVID-19 average growth rate of daily cases and deaths was observed. There was also a relationship between temperature and cumulative incidence of daily COVID-19 cases and deaths. Previous studies have shown that temperature was also an important factor in the survival and transmission of other viruses, such as SARS-CoV and MERS-CoV (Bi et al. 2007; Casanova et al. 2010; Chan et al. 2011; Tan et al. 2005; Van Doremalen et al. 2013). Bi et al. (2007) reported that temperature was negatively related to SARS transmission in Hong Kong and Beijing in 2003. A laboratory study was carried out with virus substitutes. This study investigated the effect of temperature on the survival of coronavirus on surfaces.

The results showed that viruses were inactivated more rapidly at $20^{\circ} \mathrm{C}$ than $4{ }^{\circ} \mathrm{C}$ (Casanova et al. 2010). Another laboratory study found that coronavirus has been stable on flat surfaces for more than 5 days at temperatures between 22 and $25^{\circ} \mathrm{C}$. Also, the results of the study demonstrated that the virus was rapidly killed at high temperatures, such as $38^{\circ} \mathrm{C}$ (Chan et al. 2011). Van Doremalen et al. (2013) also found that MERS-CoV is more stable at high temperatures than at lower temperatures. This issue revealed that COVID19 may not be eliminated without public health interventions in warmer weather. Therefore, people and governments cannot expect to eradicate this new virus at high temperatures. Several studies have reported that death from respiratory diseases increases with decreasing temperature, and it is strongly associated with low temperatures (Dadbakhsh et al. 2017; Fallah Ghalhari and Mayvaneh 2016; Gómez-Acebo et al. 2013; Macfarlane 1977), whereas another study revealed that both cold and hot weather may have adverse effects on death and respiratory diseases ( $\mathrm{Li}$ et al. 2019). In the case of exposure to cold and immune system function, it has been reported that low temperatures may suppress the function of the immune system (Shephard and Shek 1998). In particular, previous findings showed that the phagocytic function of the tested pulmonary alveolar macrophages decreased under laboratory conditions and cold stress (Luo et al. 2017). Breathing cold air can lead to bronchial contraction which, in turn, can increase susceptibility to lung infection (Martens 1998). In summary, most studies have shown that the optimum temperature for killing the virus is high and that high temperatures are detrimental to its survival (Van Doremalen et al. 2013). Moreover, some other studies have shown that temperature and humidity correlated with underlying diseases such as heart and respiratory diseases (Hajat and Haines 2002; Lin et al. 2009; Schwartz et al. 2004; Tian et al. 2012), which in turn could increase the number of COVID-19 deaths exacerbated by such underlying diseases (Chen et al. 2020; Masetti et al. 2020). However, this paper has not found the effect of high temperature on the growth rate of COVID-19 infection. One possible reason may be related to the ecological constraints of the study and diurnal temperature variation. In this regard, other laboratory studies are required to determine the underlying mechanism.

The study did not show any relationship between the growth rate of COVID-19 with temperature and humidity, but there was a relationship between the cumulative incidence rate of daily COVID-19 cases and deaths with temperature and humidity. Several researchers have confirmed that respiratory infections have increased in unusual conditions of cold weather and low humidity and low humidity may also be a major risk factor for respiratory diseases (Davis et al. 2016a, b). A 25 -year study found that humidity is an important factor in the number of deaths and low humidity may greatly increase death rates, potentially by influenza-related mechanisms (Barreca 2012). This result is similar to a study conducted in the USA (Barreca and Shimshack 2012). Breathing dry can either damage the epithelium or reduce mucus secretion, resulting in respiratory viral infection (Lowen et al. 2007). Also, the transmission of the pandemic influenza virus 
is an effective factor in cold and dry conditions (Steel et al. 2011), and the survival rate of the influenza virus has significantly increased due to the reduction in absolute humidity. This situation holds about coronavirus (Shaman and Kohn 2009), but our results indicate that the COVID-19 average growth rate of new cases and deaths had no association with absolute humidity. Tosepu et al. (2020) reported that COVID19 prevalence is significantly dependent upon the average temperature. However, it is claimed that COVID-19 prevalence is not significantly dependent upon the minimum and maximum temperatures, rainfall, and humidity (Barreca 2012). In another study, Chan et al. (2011) claimed that the higher temperatures and higher relative humidity (e.g., $38^{\circ} \mathrm{C}$ and relative humidity above $95 \%$ ) make the virus stable (Barreca and Shimshack 2012). Humidity is a weak contributor to this data. This may be because there are many countries in this data. Humidity also changes from one city to another within countries. These data are so general, and we have used the mean humidity in countries. This may be one plausible explanation for our finding that is inconsistent with previous research findings. The same is true of temperature. Our results also show the effect of wind on the COVID-19 average growth rate of daily cases and deaths. Şahin et al. (2020) indicated that wind speed and population density are correlated with COVID-19 (Şahin 2020). The spread of the virus can be affected by wind conditions. This finding that the COVID19 virus, which is not visible in the air, spreads more in the air, suggests that the spread of the virus through the air is a threat to humans, especially when the wind speed increases airflow (Coşkun et al. 2021). An important question that arises here is that can the virus spread through infectious dust or not? The answer to this question is out of the scope of the present research, and more laboratory studies and modeling should be done in this field. However, it should be noted that due to the complexity and variability of ambient wind conditions, as well as the complexity of the effect of wind on droplet transport and deposition, which strongly depends on wake flow patterns and localized secondary flow intensities between two humans, as well as wind stability (Feng et al. 2020), differences in the results of various studies can be understood.

Importantly, we did find a relationship between COVID-19 average growth rate of daily cases and deaths and AQI in our study. This may be due to the impact of AQI itself, the increase in traffic within the city, and the reduction in social distance. Other studies have reported an association between air pollution and decline in lung function, increased hospitalization, increased respiratory symptoms, and higher use of asthma medications (Jalaludin et al. 2004; Simoni et al. 2015). Several studies have examined the effects of meteorology and air pollution on acute viral respiratory infections and bronchiolitis (it is a disease associated with seasonal changes in respiratory viruses) during the early years of life (Nenna et al. 2017; Ségala et al. 2008; Vandini et al. 2013, 2015). The composition of environmental particles or particulate matter (PM) varies geographically and seasonally. This situation is due to the combination of resources at each location and time. A large body of literature shows the short-term effects of air pollution on health, but long-term air pollution also affects morbidity in the long run (Lowen et al. 2007).

Furthermore, the findings of our study showed that $\mathrm{PM}_{10}$ was positively associated with the cumulative rate of deaths in the first, second, and third 60-day intervals. The study by Yao et al. (2020) showed that there was a positive correlation between $\mathrm{PM}_{10}$ and case fatality rate (CFR) from COVID-19 in Wuhan, China. This association has also been seen with other indicators of air pollution. For example, Filippini et al. (2020) found a positive association between NO2 levels and COVID19 mortality rates, and high $\mathrm{NO} 2$ levels were associated with the spread of the infection. Also, Copat et al. (2020), in a systematic review study, highlight the important contribution of PM2.5 and NO2 as triggering the COVID-19 spread and lethality and with a lesser extent also PM10 (Copat et al. 2020; Maleki et al. 2021). Another study states that "COVID-19 daily new cases are positively related to PM and Air Quality Index" (Zoran et al. 2020). The findings of studies conducted by Conticini et al. (2020), Piazzalunga-Expert (2020), Travaglio et al. (2020), Wu et al. (2020), and Zhu et al. (2020) were consistent with the result obtained by this study. One explanation for the geographical differences in the number of cases is that high levels of pollutants may transmit viral diseases and increase their persistence in the environment (Frontera et al. 2020). A recent study suggests that the virus may survive in the aerosol for several hours (Van Doremalen et al. 2020). Air pollution may also play a stronger role when susceptibility to infection and the pulmonary defense mechanisms that lead to more severe forms of the disease increases (Frontera et al. 2020). Other noteworthy issues include prolonged exposure to air pollution that impairs lung function (Chauhan and Johnston 2003; Götschi et al. 2008) and may reduce resistance to viral infections (Yang et al. 2020), and prolonged traffic-related pollution, which is an important source of exposure. Typical inactivation of viruses is showed by phagocytosis in which macrophages prevent the virus from replicating and kill the virus-containing cells. Cytotoxic Tlymphocytes (CTLs) destroy infected cells. Such functions may likely be disrupted by exposure to air pollutants (Chauhan and Johnston 2003). Therefore, air pollution and $\mathrm{PM}_{10}$ can be among the factors affecting the epidemiological characteristics of COVID-19.

The strengths of this study are as follows:

a) This study was conducted across 210 countries affected by the COVID-19 disease. It is the most comprehensive study on the relationship between environmental factors and COVID-19 in which a large number of countries and multiple variables were included. 
b) The cumulative incidence of daily cases and death of COVID-19 based on the population size of incidence and death in these 210 countries was examined, which can help decision-makers control the emergence of daily cases and deaths.

However, there are some limitations with the present study that should be acknowledged. The first limitation of the study is that other important factors may affect COVID-19, including the number of confirmed cases, the number of deaths, and the number of recovered cases such as government intervention, medical resources, and so on. Therefore, these issues should be considered in future studies. The second limitation is the design of the ecological studies, which is the case in the present study. This issue may have some ecological fallacy. Besides, although the outdoor and indoor air conditions are similar, collecting meteorological and air pollution data is challenging at an individual scale. This similarity may be due to the problem of shutting down the air conditioning system and keeping the window open for $24 \mathrm{~h}$ in hospitals during the COVID-19 treatment. It should also be noted that a variable such as wind has its own variability and complexity that can affect the results, and in this study, we have only dealt with the effect of wind speed; attention to this issue in future studies can help find the effect of different types of winds on the spread of this disease.

The findings of this study contribute to the existing research about the COVID-19. To better understand the COVID-19 mechanism, however, it is essential to investigate more laboratory research. Besides, it is necessary to provide more observational and ecological evidence for understanding the COVID-19 consequences in the complex world of human behavior, but despite all these limitations, our results provide important implications for health and public policies. Estimates can be used to predict the place and time of death from COVID-19 in the future. Also, the prominent non-linear relationship between AQI and COVID-19 average growth rate of daily cases and deaths may particularly be useful for understanding regional changes in COVID-19 results. This could be a result of climate change. Moreover, this research demonstrates that future explorations regarding the role of AQI in COVID-19 will yield important results, but more laboratory research is needed to determine the effects of humidity, evaporation, and temperature on viral protein structure and survival.

\section{Conclusion}

This study provides evidence for the relationship between COVID-19 average growth rate of new cases and deaths, $\mathrm{AQI}$, and wind; however, the effect of AQI is greater than the wind. Besides, we found a relationship between the cumulative incidence rate of daily COVID-19 cases and deaths and AQI in our study. The study results showed that the number of daily COVID-19 cases and deaths is higher at high AQI than low AQI. We observed the most significant relationship between air pollution exposure and the cumulative rate of deaths during the second and third 60 days. It may be due to the prolonged exposure to the symptoms. AQI seems to be a more important factor than the air temperature and humidity in the COVID-19 average growth rate of daily cases and deaths.

Supplementary Information The online version contains supplementary material available at https://doi.org/10.1007/s11356-021-14322-6.

Acknowledgements The authors would like to thank Ms. A. Keivanshekouh at the Research Improvement Center of the Shiraz University of Medical Sciences for her help in editing the manuscript.

Author contribution $\mathrm{HG}$ is the lead author and guarantor and contributed to interpreting the data and revising the manuscript. $\mathrm{MV}, \mathrm{JH}, \mathrm{MH}, \mathrm{ZM}$, FMA, and SD planned the study and led the drafting and revising of the manuscript. MV, SD, AM, and FMA contributed to interpreting the data and drafting and revising the manuscript. All authors approved the submitted version of the manuscript. All authors have contributed to the preparation of the manuscript, have read, and approved the submitted manuscript. All authors listed meet the authorship criteria according to the latest guidelines of the International Committee of Medical Journal Editors and agree with the manuscript. The work is original and not under consideration by any other journal.

Funding This study was funded by the Shiraz University of Medical Sciences (grant No. 99-01-106-22381 and Approval Number Ethics IR.SUMS.REC.1399.182).

Availability of data and materials The data that support the findings of this study are available from the corresponding author, $[\mathrm{HGH}]$, upon reasonable request.

\section{Declarations}

Ethical approval The Approval Number of Ethics of the present study was "IR.SUMS.REC.1399.182."

Consent to participate Not applicable.

Consent to publish Not applicable.

Conflict of interest The authors declare no competing interests.

\section{References}

Barreca AI (2012) Climate change, humidity, and mortality in the United States. J Environ Econ Manag 63:19-34

Barreca AI, Shimshack JP (2012) Absolute humidity, temperature, and influenza mortality: 30 years of county-level evidence from the united states. Am J Epidemiol 176:S114-S122. https://doi.org/10.1093/ aje/kws259 
Bi P, Wang J, Hiller JE (2007) Weather: driving force behind the transmission of severe acute respiratory syndrome in China? Intern Med J 37:550-554. https://doi.org/10.1111/j.1445-5994.2007.01358.x

Casanova LM, Jeon S, Rutala WA, Weber DJ, Sobsey MD (2010) Effects of air temperature and relative humidity on coronavirus survival on surfaces. Appl Environ Microbiol 76:2712-2717. https://doi.org/10. 1128/AEM.02291-09

Chan KH, Peiris JSM, Lam SY, Poon LLM, Yuen KY, Seto WH (2011) The effects of temperature and relative humidity on the viability of the SARS coronavirus. Adv Virol 2011:1-7. https://doi.org/10. $1155 / 2011 / 734690$

Chauhan AJ, Johnston SL (2003) Air pollution and infection in respiratory illness. Br Med Bull 68:95-112

Chen Y, Gong X, Wang L, Guo J (2020) Effects of hypertension, diabetes and coronary heart disease on COVID-19 diseases severity: a systematic review and meta-analysis. MedRxiv. https://doi.org/10. 1101/2020.03.25.20043133

Conticini E, Frediani B, Caro D (2020) Can atmospheric pollution be considered a co-factor in extremely high level of SARS-CoV-2 lethality in Northern Italy? Environ Pollut 261:114465

Copat C, Cristaldi A, Fiore M, Grasso A, Zuccarello P, Santo Signorelli S et al (2020) The role of air pollution (PM and NO2) in COVID-19 spread and lethality: a systematic review. Environ, p 110129

Coșkun H, Yıldırım N, Gündüz S (2021) The spread of COVID-19 virus through population density and wind in Turkey cities. Sci Total Environ 751:141663. https://doi.org/10.1016/j.scitotenv.2020. 141663

Dadbakhsh M, Khanjani N, Bahrampour A, Haghighi PS (2017) Death from respiratory diseases and temperature in Shiraz, Iran (20062011). Int J Biometeorol 61:239-246. https://doi.org/10.1007/ s00484-016-1206-z

Davis RE, McGregor GR, Enfield KB (2016a) Humidity: a review and primer on atmospheric moisture and human health. Environ Res 144:106-116

Davis RE, Dougherty E, McArthur C, Huang QS, Baker MG (2016b) Cold, dry air is associated with influenza and pneumonia mortality in Auckland, New Zealand. Influenza Other Respir Viruses 10:310 313. https://doi.org/10.1111/irv.12369

Fallah Ghalhari G, Mayvaneh F (2016) Effect of air temperature and universal thermal climate index on respiratory diseases mortality in Mashhad, Iran. Arch Iran Med 19:618-624 0161909/AIM.004

Feng Y, Marchal T, Sperry T, Yi H (2020) Influence of wind and relative humidity on the social distancing effectiveness to prevent COVID19 airborne transmission: a numerical study. J Aerosol Sci 147: 105585

Filippini T, Rothman KJ, Goffi A, Ferrari F, Maffeis G, Orsini N, Vinceti M (2020) Satellite-detected tropospheric nitrogen dioxide and spread of SARS-CoV-2 infection in Northern Italy. Sci Total Environ 739:140278

Frontera A, Cianfanelli L, Vlachos K, Landoni G, Cremona G (2020) Severe air pollution links to higher mortality in COVID-19 patients: the "double-hit" hypothesis. J Infect 81:255-259. https://doi.org/10. 1016/j.jinf.2020.05.031

Gómez-Acebo I, Llorca J, Dierssen T (2013) Cold-related mortality due to cardiovascular diseases, respiratory diseases and cancer: a casecrossover study. Public Health 127:252-258. https://doi.org/10. 1016/j.puhe.2012.12.014

Götschi T, Heinrich J, Sunyer J, Künzli N (2008) Long-term effects of ambient air pollution on lung function: a review. Epidemiology 19: 690-701

Hajat S, Haines A (2002) Associations of cold temperatures with GP consultations for respiratory and cardiovascular disease amongst the elderly in London. Int J Epidemiol 31:825-830. https://doi.org/ 10.1093/ije/31.4.825

Jalaludin BB, O'Toole BI, Leeder SR (2004) Acute effects of urban ambient air pollution on respiratory symptoms, asthma medication use, and doctor visits for asthma in a cohort of Australian children. Environ Res 95:32-42. https://doi.org/10.1016/S0013-9351(03) 00038-0

Lai J, Ma S, Wang Y, Cai Z, Hu J, Wei N, Wu J, du H, Chen T, Li R, Tan H, Kang L, Yao L, Huang M, Wang H, Wang G, Liu Z, Hu S (2020) Factors associated with mental health outcomes among health care workers exposed to coronavirus disease 2019. JAMA Netw Open 3: e203976

Li M, Zhou M, Yang J, Yin P, Wang B, Liu Q (2019) Temperature, temperature extremes, and cause-specific respiratory mortality in China: a multi-city time series analysis. Air Qual Atmos Health 12:539-548. https://doi.org/10.1007/s11869-019-00670-3

Lin S, Luo M, Walker RJ, Liu X, Hwang SA, Chinery R (2009) Extreme high temperatures and hospital admissions for respiratory and cardiovascular diseases. Epidemiology 20:738-746. https://doi.org/10. 1097/EDE.0b013e3181ad5522

Lowen AC, Mubareka S, Steel J, Palese P (2007) Influenza virus transmission is dependent on relative humidity and temperature. PLoS Pathog 3:1470-1476. https://doi.org/10.1371/journal.ppat.0030151

Luo B, Liu J, Fei G, Han T, Zhang K, Wang L, Shi H, Zhang L, Ruan Y, Niu J (2017) Impact of probable interaction of low temperature and ambient fine particulate matter on the function of rats alveolar macrophages. Environ Toxicol Pharmacol 49:172-178. https://doi.org/ 10.1016/j.etap.2016.12.011

Macfarlane A (1977) Daily mortality and environment in English conurbations. I: Air pollution, low temperature, and influenza in Greater London. Br J Prev Soc Med 31:54-61. https://doi.org/10.1136/jech. 31.1.54

Maleki M, Anvari E, Hopke PK, Noorimotlagh Z, Mirzaee SA (2021) An updated systematic review on the association between atmospheric particulate matter pollution and prevalence of SARS-CoV-2. Environ, p 110898

Martens WJM (1998) Climate change, thermal stress and mortality changes. Soc Sci Med 46:331-344. https://doi.org/10.1016/S02779536(97)00162-7

Masetti C, Generali E, Colapietro F, Voza A, Cecconi M, Messina A, Omodei P, Angelini C, Ciccarelli M, Badalamenti S, Canonica GW, Lleo A, Aghemo A, the for the Humanitas Covid-19 Task Force (2020) High mortality in COVID-19 patients with mild respiratory disease. Eur J Clin Investig 50:e13314. https://doi.org/10.1111/eci. 13314

Nenna R, Evangelisti M, Frassanito A, Scagnolari C, Pierangeli A, Antonelli G, Nicolai A, Arima S, Moretti C, Papoff P, Villa MP, Midulla F (2017) Respiratory syncytial virus bronchiolitis, weather conditions and air pollution in an Italian urban area: an observational study. Environ Res 158:188-193. https://doi.org/10.1016/j.envres. 2017.06.014

Park JE, Son WS, Ryu Y, Choi SB, Kwon O, Ahn I (2020) Effects of temperature, humidity, and diurnal temperature range on influenza incidence in a temperate region. Influenza Other Respir Viruses 14: 11-18. https://doi.org/10.1111/irv.12682

Piazzalunga-Expert A (2020) Evaluation of the potential relationship between particulate matter (PM) pollution and COVID-19 infection spread in Italy. mimeo

Qu G, Li X, Hu L, Jiang G (2020) An imperative need for research on the role of environmental factors in transmission of novel coronavirus (COVID-19). In: ACS Publications

Şahin M (2020) Impact of weather on COVID-19 pandemic in Turkey. Sci Total Environ 728:138810. https://doi.org/10.1016/j.scitotenv. 2020.138810

Schwartz J, Samet JM, Patz JA (2004) Hospital admissions for heart disease: the effects of temperature and humidity. Epidemiology 15:755-761. https://doi.org/10.1097/01.ede.0000134875.15919.0f

Ségala C, Poizeau D, Mesbah M, Willems S, Maidenberg M (2008) Winter air pollution and infant bronchiolitis in Paris. Environ Res 106:96-100. https://doi.org/10.1016/j.envres.2007.05.003 
Shaman J, Kohn M (2009) Absolute humidity modulates influenza survival, transmission, and seasonality. Proc Natl Acad Sci U S A 106: 3243-3248. https://doi.org/10.1073/pnas.0806852106

Shaman J, Pitzer VE, Viboud C, Grenfell BT, Lipsitch M (2010) Absolute humidity and the seasonal onset of influenza in the continental United States. PLoS Biol 8:e1000316

Shephard RJ, Shek PN (1998) Cold exposure and immune function. Can J Physiol Pharmacol 76:828-836. https://doi.org/10.1139/y98-097

Simoni M, Baldacci S, Maio S, Cerrai S, Sarno G, Viegi G (2015) Adverse effects of outdoor pollution in the elderly. J Thorac Dis 7: $34-45$

Steel J, Palese P, Lowen AC (2011) Transmission of a 2009 pandemic influenza virus shows a sensitivity to temperature and humidity similar to that of an H3N2 seasonal strain. J Virol 85:1400-1402. https://doi.org/10.1128/jvi.02186-10

Tan J, Mu L, Huang J, Yu S, Chen B, Yin J (2005) An initial investigation of the association between the SARS outbreak and weather: with the view of the environmental temperature and its variation. J Epidemiol Community Health 59:186-192. https://doi.org/10.1136/jech.2004. 020180

Tian Z, Li S, Zhang J, Jaakkola JJK, Guo Y (2012) Ambient temperature and coronary heart disease mortality in Beijing, China: a time series study. Environ Health 11:56. https://doi.org/10.1186/1476-069X$11-56$

Tosepu R, Gunawan J, Effendy DS, Lestari H, Bahar H, Asfian P (2020) Correlation between weather and Covid-19 pandemic in Jakarta, Indonesia. Sci Total Environ 725:138436

Travaglio M, Yu Y, Popovic R, et al (2020) Links between air pollution and COVID-19 in England. Environ Pollut 268:115859

Van Doremalen N, Bushmaker T, Munster VJ (2013) Stability of Middle East respiratory syndrome coronavirus (MERSCoV) under different environmental conditions. Eurosurveillance 18(38):20590

Van Doremalen N, Bushmaker T, Morris DH, Holbrook MG, Gamble A, Williamson BN, Tamin A, Harcourt JL, Thornburg NJ, Gerber SI et al (2020) Aerosol and surface stability of SARS-CoV-2 as compared with SARS-CoV-1. N Engl J Med 382:1564-1567

Vandini S, Corvaglia L, Alessandroni R, Aquilano G, Marsico C, Spinelli M, Lanari M, Faldella G (2013) Respiratory syncytial virus infection in infants and correlation with meteorological factors and air pollutants. Ital J Pediatr 39:1. https://doi.org/10.1186/1824-7288-39-1
Vandini S, Bottau P, Faldella G, Lanari M (2015) Immunological, viral, environmental, and individual factors modulating lung immune response to respiratory syncytial virus. Biomed Res Int 2015:1-7. https://doi.org/10.1155/2015/875723

Wang C, Horby PW, Hayden FG, Gao GF (2020a) A novel coronavirus outbreak of global health concern. Lancet 395:470-473

Wang M, Jiang A, Gong L, Lu L, Guo, W, Li C, Zheng J, Li C, Yang B, Zeng J, Chen Y, Li H (2020b) Temperature significant change COVID-19 Transmission in 429 cities. medrxiv

Wood SN (2017) Generalized additive models: an introduction with R: CRC press

Wu X, Nethery RC, Sabath BM, Braun D, Dominici F (2020) Exposure to air pollution and COVID-19 mortality in the United States: A nationwide cross-sectional study. medRxiv. https://doi.org/10. $1101 / 2020.04 .05 .20054502$

Yang L, Li C, Tang X (2020) The impact of PM2.5 on the host defense of respiratory system. Front. Cell. Dev Biol 8:91

Yao Y, Pan J, Liu Z et al (2020) Temporal association between particulate matter pollution and case fatality rate of COVID-19 in Wuhan, China. medRxiv 189:109941

Yousefi M, Oskoei V, Jafari AJ, Farzadkia M, Firooz MH, Abdollahinejad B, Torkashvand J (2021) Municipal solid waste management during COVID-19 pandemic: effects and repercussions. Environ Sci Pollut Res, pp 1-10

Yu ITS, Li Y, Wong TW, Tam W, Chan AT, Lee JHW, Leung DYC, Ho $\mathrm{T}$ (2004) Evidence of airborne transmission of the severe acute respiratory syndrome virus. N Engl J Med 350:1731-1739. https://doi. org/10.1056/nejmoa032867

Zhu Y, Xie J, Huang F, Cao L (2020) Association between short-term exposure to air pollution and COVID-19 infection: evidence from China. Sci Total Environ 727:138704. https://doi.org/10.1016/j. scitotenv.2020.138704

Zoran MA, Savastru RS, Savastru DM, Tautan MN (2020) Assessing the relationship between surface levels of PM2. 5 and PM10 particulate matter impact on COVID-19 in Milan, Italy. Sci Total Environ 738: 139825

Publisher's note Springer Nature remains neutral with regard to jurisdictional claims in published maps and institutional affiliations. 